\title{
Barriers to Implementing the Circular Economy in the Construction Industry: A Critical Review
}

\author{
Rabia Charef ${ }^{1}$, Jean-Claude Morel ${ }^{2, *}$ and Kambiz Rakhshan ${ }^{3}$ \\ 1 Faculty of Engineering, Environment and Computing, Coventry University, Coventry CV1 5FB, UK; \\ r.charef69@gmail.com \\ 2 Laboratory of Tribology and System Dynamics, National School of State Public Works (ENTPE), \\ 69120 Lyon, France \\ 3 Leeds Sustainability Institute, Leeds Beckett University, Woodhouse Lane, Leeds LS2 8AG, UK; \\ rakhshak@uni.coventry.ac.uk \\ * Correspondence: jeanclaude.morel@entpe.fr
}

\section{check for} updates

Citation: Charef, R.; Morel, J.-C.; Rakhshan, K. Barriers to Implementing the Circular Economy in the Construction Industry: A Critical Review. Sustainability 2021, 13, 12989. https://doi.org/10.3390/ su132312989

Academic Editors: Nicola Raimo,

Filippo Vitolla, Ornella Malandrino, Benedetta Esposito and Paris Fokaides

Received: 25 October 2021

Accepted: 17 November 2021

Published: 24 November 2021

Publisher's Note: MDPI stays neutral with regard to jurisdictional claims in published maps and institutional affiliations.

Copyright: (c) 2021 by the authors. Licensee MDPI, Basel, Switzerland This article is an open access article distributed under the terms and conditions of the Creative Commons Attribution (CC BY) license (https:// creativecommons.org/licenses/by/ $4.0 /)$.

\begin{abstract}
To facilitate the adoption of the circular economy $(\mathrm{CE})$ in the architecture, engineering and construction (AEC) sector, some authors have demonstrated the potential of recent designs that take into account the sustainable management of an asset's end-of-life (EOL), providing an alternative to the dominant designs that end with demolition. However, there is no review of the literature that encompasses a large range of sustainable designs in the current CE context. This paper provides a critical review of journal papers that deal with the barriers to implementing sustainable designs and approaches to the EOL management of assets that have the potential to fulfil the principles of the CE. Eighteen approaches related to prefabrication, design for change, design for deconstruction, reverse logistics, waste management and closed-loop systems were found. Through an analysis of the barriers that are common among these 18 approaches, we classified them into six different categories (organisational, economical, technical, social, political and environmental). Two Sankey diagrams illustrate the interrelation between the barriers, their categories and the 18 approaches. The diagrams clearly show that most of the barriers are common to multiple approaches and that most of the barriers relate to organisational concerns. The study gives a detailed map of the barriers that would help stakeholders from the AEC sector develop strategies to overcome the current obstacles in the shift to a CE.
\end{abstract}

Keywords: sustainable asset lifecycle; circular economy; design for deconstruction; barriers; sustainable approach; critical literature review

\section{Introduction}

Since the 1973 oil embargo, the architecture, engineering and construction (AEC) sector has had to reduce the energy it uses through various active and passive measures, including increasing the insulation of buildings $[1,2]$. To reduce heat loss from the envelope, builders add insulation to the full perimeter of buildings at the cost of consuming more primary resources to produce insulation materials. Similar processes occur with double/triple glazing or building-integrated photovoltaics, resulting in more pressure on building component production and its corollary consumption of natural resources. Inevitably, stakeholders in this sector have to tackle various related challenges, including the scarcity of raw material resources and the production of megatonnes of waste [3].

Waste is generated throughout the lifecycle of an asset. However, the end-of-life (EOL) phase of assets is the least sustainable phase, given the amount of waste generated by the demolition process. Demolition is responsible for $50 \%$ of all waste produced by the AEC sector worldwide [4]. In the UK, 30\% of the total waste sent to landfills comes from the demolition of buildings, costing GBP 200 million annually [5]. That is why the EOL management of assets and the construction and demolition waste (CDW) that is often 
produced at this stage are of increasing interest to academic researchers [6], who seek to shift the sector into a new paradigm with the advent of the circular economy (CE) [7]. Recently, the Ellen MacArthur Foundation [8] has contributed to the shift from the linear system to the CE for the manufacturing industry $[9,10]$. As an example, at the European Union level, the CE implementation action plan was initiated in 2015 [11]. After five years of implementation in the industry, some authors have noticed some shortcomings. First, recycling has been developed most substantially [11], despite the fact that it is the worst option on the scale of the "10Rs", just before the "R" of "Recover" [12]. Secondly, EU policies focus on "end of pipe" solutions without addressing "the many socio-ecological implications of a circularity transition" [13].

In the specific case of the AEC sector, the linear approach is the dominant method in the "design for construction", with the EOL managed by demolition [14]. There is no consensus on a definition of the circularity of a building. The reason might be due to a lack of familiarity with what the notion of the CE means for the AEC sector compared with the manufacturing industry. Moreover, the nature of a building is very different from a given manufactured product, in terms of its use and fabrication process. Indeed, in the construction industry, each owner (private, public or company) wishes to have a bespoke building and not a standard one. Moreover, the management of a building from its construction phase to its demolition involves a wide range of stakeholders with different skills and stakes, as illustrated by some authors [15]. Lastly, the timescale of the different phases of a building's lifecycle varies drastically and is considerably long during its operation (typically lasting a minimum of 30 years).

Although the implementation of the CE in the AEC sector is relatively new [16], some authors have already studied alternative approaches that have the potential to fulfil the CE requirements. For example, Ghisellini et al. [17] have linked sustainable buildings and cleaner production to the CE. Some authors have associated the design for deconstruction (DfD) approach to the CE [18], whereas this concept of design for $X$ is already developed in other sectors of the industry [19]. Another example is the extensive focus on resource use and CDW management (e.g., [20]) at the expense of the investigation into alternative approaches, such as supply chain integration, building designs, offsite manufacturing, among others [21]. Moreover, as the AEC sector is currently experiencing the digital revolution (mainly through building information modelling, or BIM), some authors have developed specific BIM uses for overcoming the barriers to the adoption of a CE [22]. However, this research area is still in its infancy, and as such, it faces a lack of common understanding which leads to the inconsistent application of terminologies, especially among architects and contractors [23]. More recently, in response to the lack of consensus and to clarify the processes along the asset lifecycle, some authors have developed a classification of the current alternative design approaches that have the potential to fulfil the CE requirements [24]. This classification clarifies and illustrates the current diversity of existing alternative approaches with five central categories (prefabrication, design for change, design for deconstruction, reverse logistics, and closed-loop systems). Although this current research has fueled the quest for clarity, there are still no studies that provide an overview of the barriers facing sustainable design approaches. Indeed, studies found in the literature typically explore barriers associated with a particular sustainable approach, such as the implementation of reverse logistics [25], construction waste reduction, reuse and recycling [26], among others. More recently, the impediments associated with the CE approach are at the centre of the concerns of some authors [27]. However, none of these studies have targeted the overall view of the barriers associated with sustainable approaches, as defined by [24].

This article aims to analyse the barriers found in the literature that are preventing the AEC sector from shifting to a CE. To fulfil this aim, the following objectives are defined:

1. To extract from journal papers the barriers to the implementation of approaches related to prefabrication, design for change, design for deconstruction, reverse logistics, waste management and closed-loop systems. 
2. To classify the barriers into categories and extract the interrelation between the barriers, their categories and the selected approaches.

\section{Method}

Figure 1 presents the three stages of the overall method to establish an understanding of the barriers identified in the literature that are hindering the development of the CE in the AEC sector. At Stage 1, we selected the journal articles for the review. First, the approaches that have the potential to help implement the CE in the AEC sector are selected (Points 1 and 2, developed in Section 2.1). Second, the journal articles dealing with the barriers to those approaches are searched for (Section 2.2). Stage 2 is dedicated to the analysis. First, how the barriers could be classified into categories was investigated (Section 2.3). Second, the results are eventually illustrated in Stage 3 by the two Sankey diagrams.

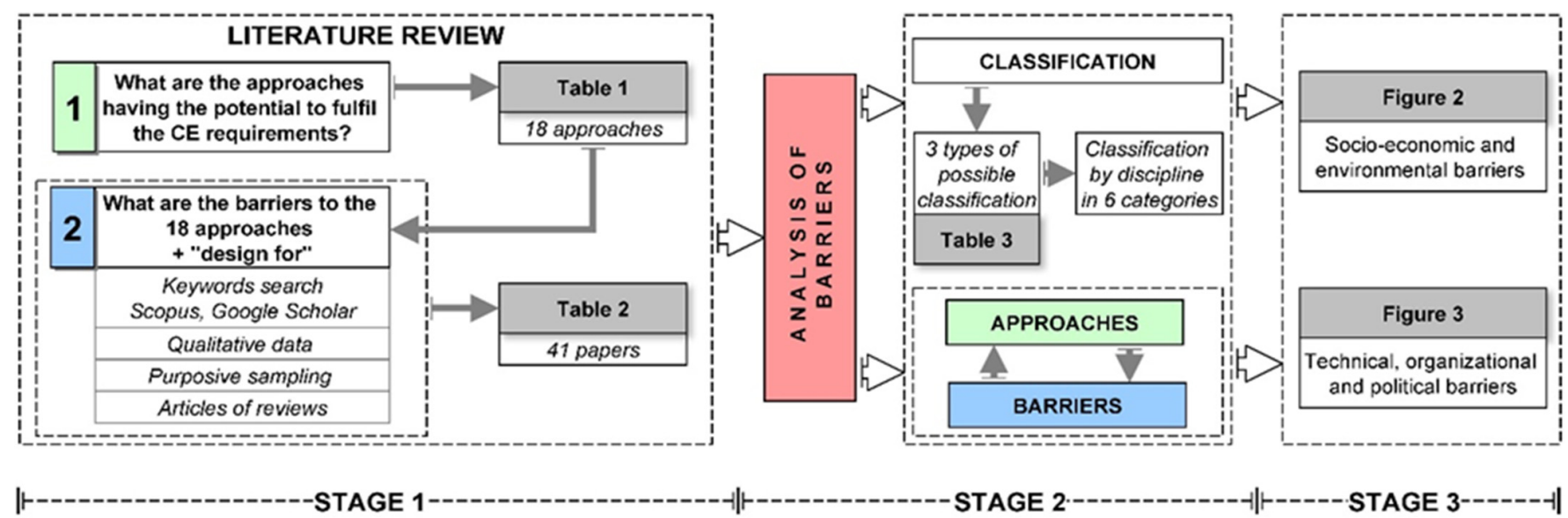

Figure 1. Graphical image of the methodological framework with three stages.

\subsection{The Studied Approaches}

Eighteen approaches, listed in Table 1, were extracted from previous work conducted on the identification, definition, and classification of asset lifecycle strategies for the CE [24]. In this previous work, the authors provided a synthesis of the literature to clarify the approaches that are related to the asset lifecycle in the context of the CE. The definitions of sets of approaches were analysed to clarify whether they were compliant with a CE or recycling and reuse economy CE [24]. Most of those approaches are alternative design approaches that have the potential to fulfil the $\mathrm{CE}$ requirements. However, some approaches deal with CDW management, given that it is a crucial stage in the $\mathrm{CE}$ that must be brought down to zero waste. The barriers linked to life cycle assessment (LCA) in the AEC sector were also investigated, because it is a method that is key in the context of the $\mathrm{CE}$ where circularity indicators are yet to be properly developed in the AEC sector. Most of the approaches are dual, with the approach linked to the design for the approach (e.g., for reverse logistics (RL) and design for reverse logistics (DfRL) - see Table 1). In the following, to simplify the reading, the comments will specify only the approach and not its associated "design for" approach (e.g., simply RL, not RL-DfRL).

\subsection{The Search Method for Papers Dealing with Barriers to the 18 Approaches}

This research has targeted only qualitative data in peer-reviewed journals to ensure the quality of the secondary data [28]. Knowing the 18 approaches has guided the extraction of appropriate keywords. For example, in the case of DfD, the keywords would be "barriers" and "deconstruction" (or "dismantling", or "disassembly", or "demountable", among others). The papers were searched for in two databases (Scopus and Google Scholar) and purposive sampling was used as defined by Grant and Booth [29] to select the outputs. Articles of review on a specific approach were privileged to ensure that we obtain the whole picture of the approach and its barriers, Table 2. 
Table 1. Acronyms of the 18 studied approaches.

\begin{tabular}{ll}
\hline Acronyms & Approaches \\
\hline 3Rs-Df3Rs & Reduce, Reuse, Recycle/Design for Reduce, Reuse, Recycle \\
AR-DfAR & Adaptive Reuse/Design for Adaptive Reuse \\
CDW Mana & Construction and Demolition Waste Management \\
CDW Mini & Construction and Demolition Waste Minimisation \\
CE-DfCE & Circular Economy/Design for Circular Economy \\
CL-DfCL & Closed loops/Design for Closed loops \\
Cy & Constructability \\
De-DfD & Deconstruction/Design for Deconstruction \\
Disa-DfDisa & Disassembly/Design for Disassembly \\
Dis-DfDis & Dismantle/Design for Dismantle \\
IFD-DfIFD & Industrialised, Flexible and Demountable/Design for Industrialised, \\
LCA & Flexible and Demountable buildings \\
MA & Lifecycle Assessment \\
PFA-DfPFA & Manufacture and Assembly/Design for Manufacture and Assembly \\
RL-DfRL & Prefabrication/Design for Prefabrication \\
SB-DfSB & Reverse Logistics/Design for Reverse Logistics \\
SD & Sustainable Building/Design for Sustainable Building \\
TB-DfTB & Selective Demolition \\
\hline
\end{tabular}

\subsection{The Classification of the Barriers}

Given the number of barriers in the literature, we sought to classify them into categories and subcategories to facilitate the analysis and the discussion. According to the literature, outlined in Table 3, three main types of categories were used, namely those linked to:

1. A discipline (economy, environment, culture, among others).

2. A specific stakeholder (owners, designers, among others).

3. A construction phase (design, in use, etc.).

One of the weaknesses of the construction industry is its siloed working methods where the phases and stakeholders are divided, with poor communications in between. In the particular context of the $\mathrm{CE}$, it is crucial to implement a more holistic approach, involving all of the stakeholders and therefore all of the asset phases as described by [15]. The choice of the disciplines as macro-categories is motivated by the need to cover the whole of the asset lifecycle and all of the stakeholders involved in the asset lifecycle in line with the holistic approach required to implement a CE [15]. Moreover, a classification by discipline gives us the ability to highlight that the technical barriers are only a part of the picture, despite the fact that there is a huge scientific literature focused only on technical barriers. The label of the categories is derived from the literature (see Table 3) especially Huuhka and Hakanen (2015), who used four categories for their barriers: (i) economic, (ii) social, (iii) ecological and (iv) technological. Following this, two categories (organisational and political) were added by Rakhshan et al. (2020). For this study, six main categories are therefore used (economic, sociological, political, organizational, technological and environmental). Within these categories, some subcategories related to specific stakeholders or phases are added when necessary. 
Table 2. List of the articles analysed and used to build the Sankey diagrams.

\begin{tabular}{|c|c|c|}
\hline Authors & Article Title & Type of Data (LR = Literature Review) \\
\hline Ajayi et al. (2015) [30] & $\begin{array}{l}\text { Waste effectiveness of the construction industry: Understanding the impediments and requisites for } \\
\text { improvements }\end{array}$ & LR \\
\hline Akanbi et al. (2018) [31] & Salvaging building materials in a circular economy: A BIM-based whole-life performance estimator & Interviews + questionnaire \\
\hline Akinade et al. (2020) [32] & Design for deconstruction using a circular economy approach: Barriers and strategies for improvement & Questionnaire + literature review \\
\hline Bouzon et al. (2015) [33] & Reverse logistics drivers: empirical evidence from a case study in an emerging economy & LR \\
\hline Brancart et al. (2017) [34] & Transformable structures: Materialising design for change & LR \\
\hline Carvalho Machado et al. (2018) [35] & $\begin{array}{l}\text { Analysis of Guidelines and Identification of Characteristics Influencing the Deconstruction Potential of } \\
\text { Buildings }\end{array}$ & Case study \\
\hline Chileshe et al. (2015) [25] & Barriers to implementing reverse logistics in South Australian construction organisations & LR \\
\hline Chileshe et al. (2016) [36] & Drivers for adopting reverse logistics in the construction industry: A qualitative study & Case study \\
\hline Couto and Couto (2010) [37] & $\begin{array}{l}\text { Analysis of Barriers and the Potential for Exploration of Deconstruction Techniques in Portuguese } \\
\text { Construction Sites }\end{array}$ & LR + case studies \\
\hline Crowther, P. (2002) [38] & Design for buildability and the deconstruction consequences & LR \\
\hline Cruz Rios et al. (2015) [40] & Design for Disassembly and Deconstruction-Challenges and Opportunities & Case study/modelling \\
\hline Diyamandoglu and Fortuna (2015) [41] & Deconstruction of wood-framed houses: Material recovery and environmental impact & Questionnaire + case study \\
\hline Ferreira Correia et al. (2021) [42] & Plan to Overcome Barriers to Reverse Logistics in CDW: Survey of the Construction Industry & LR+Questionnaire \\
\hline Forsythe, P. (2011) [43] & Drivers of Housing Demolition Decision Making and the Impact on Timber Waste Management & LR + focus groups \\
\hline Gorgolewski, M. (2008) [44] & Designing with reused building components: Some challenges & Case studies \\
\hline Leigh and Patterson (2006) [45] & Deconstructing to Redevelop & LR + case study + model \\
\hline Hakkinen and Belloni (2011) [46] & Barriers and drivers for sustainable building & Semi-structured interviews \\
\hline Hosseini et al. (2014) [47] & Reverse Logistics for the Construction Industry: Lessons from the Manufacturing Context & LR+ focus group + model \\
\hline Hosseini et al. (2015) [48] & Reverse logistics in the construction industry & Questionnaire + case study \\
\hline Huuhka and Hakanen (2015) [49] & Potential and barriers for reusing load-bearing building components in Finland & Case study \\
\hline Inglis, M. (2007) [50] & Construction and Demolition waste-Best practice and cost-saving & Case study \\
\hline Jaillon and Poon (2010) [51] & Design issues of using prefabrication in Hong Kong building construction & LR \\
\hline
\end{tabular}


Table 2. Cont.

\begin{tabular}{|c|c|c|}
\hline Authors & Article Title & Type of Data (LR = Literature Review) \\
\hline Jaillon and Poon (2014) [52] & Lifecycle design and prefabrication in buildings: A review and case studies in Hong Kong & LR \\
\hline Kibert, C. J. (2003) [53] & Deconstruction: The start of a sustainable materials strategy for the built environment & Case study \\
\hline Kifokeris and Xenidis (2017) [54] & Constructability: Outline of Past, Present, and Future Research & LR + case studies \\
\hline Kim et al. (2017) [55] & An estimation framework for building information modelling (BIM)-based demolition waste by type & $\mathrm{LR}+$ case studies \\
\hline Knecht B. (2004) [56] & Designing for Disassembly and Deconstruction & LR \\
\hline Kohler, N., and Yang, W. (2007) [57] & Long-term management of building stocks. & Case study \\
\hline Pulaski et al. (2004) [59] & Design for Deconstruction & LR + model \\
\hline Río Merino and Gracia (2010) [60] & Sustainable construction: Construction and demolition waste reconsidered & LR \\
\hline Sanchez and Haas (2018) [61] & Capital project planning for a circular economy & LR \\
\hline Sassi, P. (2008) [62] & Defining closed-loop material cycle construction & LR \\
\hline Tingley and Davison (2012) [63] & Developing an LCA methodology to account for the environmental benefits of design for deconstruction & LR+model \\
\hline Xanthopoulos et al. (2009) [64] & $\begin{array}{l}\text { Reverse logistics processes of multi-type end-of-life buildings/construction sites: An integrated } \\
\text { optimization framework }\end{array}$ & LR \\
\hline Yuan et al. (2018) [65] & Design for Manufacture and Assembly-oriented parametric design of prefabricated buildings & Case study \\
\hline Zaman et al. (2018) [66] & $\begin{array}{l}\text { Resource Harvesting through a Systematic Deconstruction of the Residential House: A Case Study of the } \\
\text { 'Whole House Reuse' Project in Christchurch, New Zealand }\end{array}$ & Survey \\
\hline
\end{tabular}


Table 3. The different types of barrier categories found in the literature.

\begin{tabular}{|c|c|}
\hline Authors & Categories \\
\hline (Hosseini et al., 2014) [47] & External. \\
\hline (Chileshe et al., 2016) [36] & 2. Internal (to the manufacture and building industry). \\
\hline \multirow{3}{*}{ (Chileshe et al., 2015) [25] } & The authors split the external barriers into two subcategories: \\
\hline & $\begin{array}{l}\text { 1. "Environmental barriers", referring to barriers imposed by the prevailing } \\
\text { business environment in the industry. }\end{array}$ \\
\hline & $\begin{array}{l}\text { 2. Barriers due to the nature of construction products (e.g., buildings) and } \\
\text { their activities. }\end{array}$ \\
\hline
\end{tabular}

(Abdulrahman et al., 2014) [67]

Authors grouped the RL implementation barriers relevant to the Chinese context into four categories: (i) management, (ii) financial, (iii) policy and (iv) infrastructure.

Authors have classified the barriers to their multi-perspective framework for

(Bouzon, Govindan, and Rodriguez, 2018) [68]

RL into three categories: (i) governmental perspective, (ii) organisational perspective and (iii) consumers' perspective.

(i) Steering mechanisms: informative regulatory instruments (mandatory labelling)_economic and market-based instruments (certificate schemes), fiscal instruments and incentives (taxation and support)—voluntary action (public leadership programmes); (ii) Economics; (iii) Client understanding;

(Häkkinen and Belloni, 2011) [46]

(iv) Process: procurement and tendering, timing, cooperation and networking);

(v) Underpinning knowledge: knowledge and common language, availability of methods and tools, innovation (including for normative regulatory instruments, e.g., building codes).

(Huuhka and Hakanen, 2015) [49]

Barriers to reusing load-bearing building components in Finland in four categories: (i) economic, (ii) social, (iii) ecological and

(iv) technological barriers.

(Rakhshan et al., 2020) [3]

Barriers to reusing load-bearing building components in six categories:

(i) economics, (ii) environmental, (iii) organisational, (iv) social,

(v) technological and (vi) regulatory barriers.

Barriers to constructability implementation in five categories: (i) general

(Kifokeris and Xenidis, 2017) [54] barriers, (ii) owner barriers, (iii) designer barriers, (iv) contractor barriers and (v) project-specific barriers.

(Park and Tucker, 2016) [69] Barriers raised by stakeholders (end users, developers, etc.).

\section{Results and Discussion}

Sankey diagrams (Figures 2 and 3) are used as a visualisation tool to analyze the interplay between the barriers (structured in different categories and subcategories) and the 18 approaches. Figure 2 presents the sociological, economic and environmental barriers, given that those three categories are the basis of sustainable development.

\subsection{Environmental Barriers}

The environmental barriers are less prominent than the socio-economic ones (Figure 2). They are mainly limited to the EOL phase of the asset (CDW management and selective demolition). In the cases of deconstruction (De), RL and adaptive reuse (AR), the issue of space for storage is cited by [25]. The site access limitation is also cited by [51]. Some authors have also noticed the existence of lead and asbestos in old buildings when dealing with RL, the 3 Rs and CDW management $[56,58,60]$. Those authors are not linking the high pollutant materials to environmental issues, but to the additional costs of processing such materials. However, the process leads to environmental issues because waste ends up in landfills. The fact that some authors and stakeholders do not directly link pollution to environmental issues but to cost may be related to the lack of awareness of the impact that 
these processes have on the environment. This is made more apparent with prominence of the economic barriers (cost and market) (Figure 2).

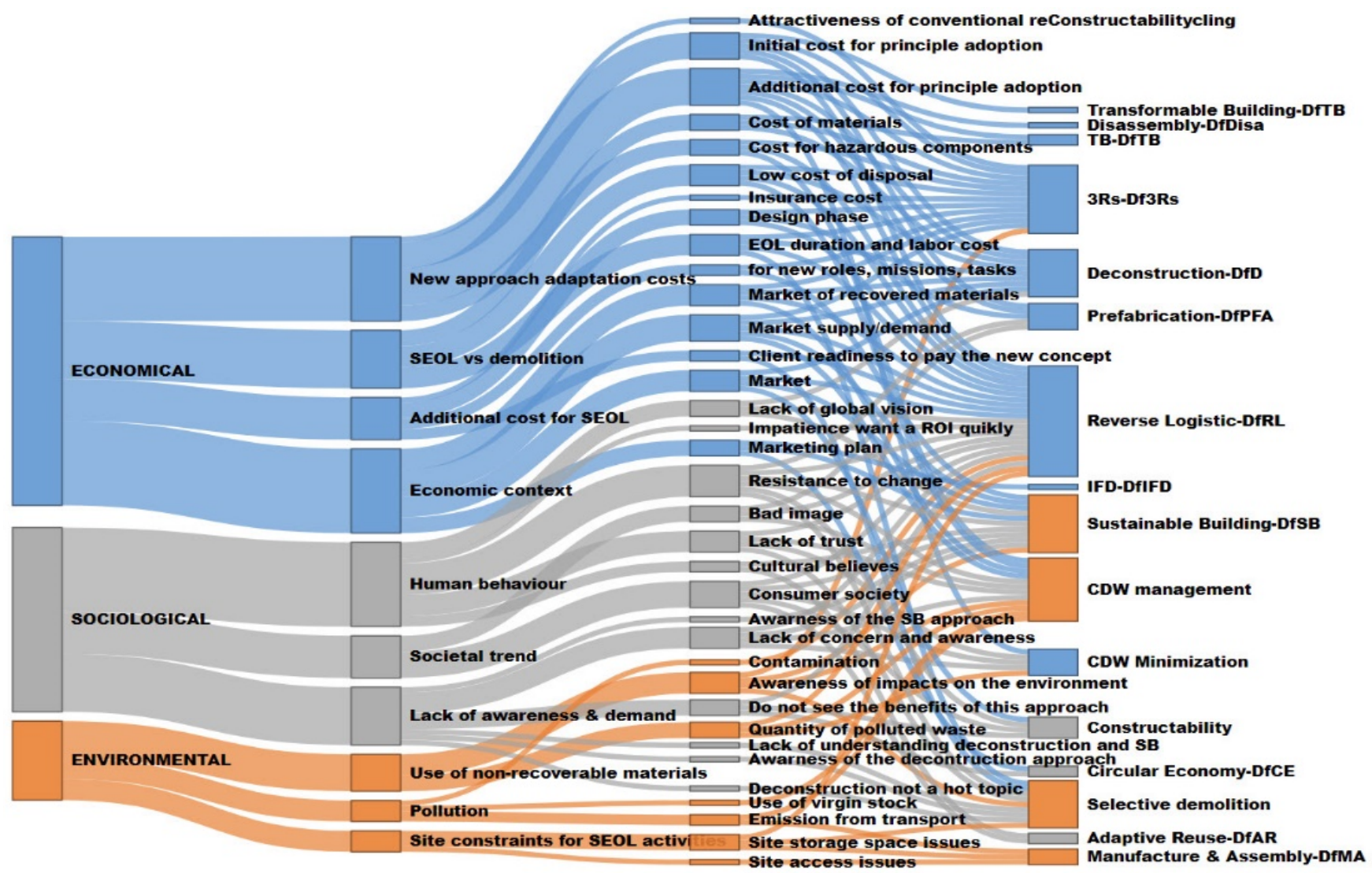

Figure 2. Outline of the sociological, economic and environmental barriers to alternative approaches identified in the literature.

Many studies have identified the lack of strong evidence of the environmental and sustainability benefits of using well-designed approaches, such as De, SB (sustainable buildings), the 3Rs (reduce, reuse, recycle), AR and CDW minimisation [46]. Other authors raised the exposure to health and safety risks from encountering contaminated materials as an essential barrier $[25,39]$. However, this topic is also linked to a social issue because health and safety are determined by the appraisal of the risks by society.

Direct, specific impacts have been identified by Sassi [62] in the recycling process, where the loss of material mass required additional virgin feedstock to be added. Other authors have identified the emissions from transport and reconditioning for the 3Rs and PFA (prefabrication) approaches [40,51].

\subsection{Economic Barriers}

The obstacles arising from factors related to the economic context (Figure 2) demonstrate that the markets built around sustainable buildings are, in many cases, insufficient. For example, the marketing plan of the industrial, flexible and demountable approach (IFD) is found to be inappropriate [52]. For SB, the lack of client demand is a barrier [46]. These shortcomings include the lack of demand for second-hand, reused and recycled materials and products [47]. The other factor is due to the constrictive search for profitability, which does not permit any risks to arise from innovation or changes to the current processes [54]. Deconstruction faces economic barriers because it is more expensive than demolition, demanding more time and labour to recover comparably low-cost construction materials [44]. Several authors have argued that the low cost of construction materials compared to recovered/recycled materials is the problem in the cases of De and the 3Rs [43]. Moreover, the standard construction and demolition practices are focused on the fastest and most 
economical way to finish the job in the case of the 3Rs [44]. Lastly, obstacles are caused by the shortcomings of the recycling processes of conventional materials. For example, a building's aluminium scraps are challenging to recover economically [58], and the recycled aggregates have a considerably lower price than that of the natural materials, due to their poorer quality. The relatively low cost of disposing CDW materials in landfills is also cited as a barrier by many authors, in the cases of De, RL, the 3Rs and PFA [58]. Some authors have also noticed the labour-intensive nature of the deconstruction and reuse processes [33]. Moreover, additional time is necessary in the cases of SD, De, and the 3Rs compared to conventional processes. This extra time results in extra costs [33].

The main economic subcategory relates to the costs attributed to the approach ("new approach adoption cost" in Figure 2). The design phase embodies additional costs due to more work needing to be performed in the case of RL, the 3Rs and PFA [52]. Although no additional costs attributed to the construction phase were found, some costs related to the necessary adaptations to a new approach (or to adopt new approaches) were noted. Several authors have identified such additional costs for adopting the following approaches: De, RL, TB (transformable buildings), Dis (dismantle), the 3Rs, CDWmini (CDW minimisation) and PFA [25]. The additional cost is also due to the management of hazardous components. For example, the existence of lead and asbestos in old buildings makes the process of deconstruction costly and time consuming because the cost of separating the materials to be recycled from contaminating materials is high $[58,60]$. Another cost of adopting a new approach is the additional initial cost (i.e., the higher cost of the initial investment in the project) cited by many authors, concerning the following approaches: De, RL and PFA $[25,30,36,37,51,52,66]$. Lastly, the additional costs due to higher insurance fees are a barrier reported by some authors for the 3Rs approach [70].

Some authors have spotted barriers linked to the quantification and sales involved in the approaches. In the case of De, Jaillon and Poon [52] have noticed that the economic benefits are not well established. Similarly, Xanthopoulos et al. [64] highlighted the lack of establishment for the economic and environmental benefits of CDW management. In the case of SB, Häkkinen and Belloni [46] have noticed the lack of understanding of business cases. Finally, in the case of AR, Chileshe et al. [25] have noted the significant differences in the distribution of the construction budget.

Another type of obstacle valid for the 3Rs approach is the necessity of planning and paying upfront early in the asset's lifecycle, which is impossible without the willingness of the client [44]. At this stage, it is often the case that the contractor has not been appointed yet, so the client has to spend money upfront purchasing materials, which many clients will not be willing to do.

\subsection{Sociological Barriers}

Sociological barriers deal with social issues, focusing on cultural (societal trends), psychological (human behaviour) and personal characteristics (lack of awareness and demand). The main subcategory is "human behaviour" and the most cited barrier is "resistance to change" (Figure 2). Cultural beliefs are involved in the case of sustainable buildings, which notably face the barrier of a low-risk culture [46], as does the case of CDW minimisation [30]. The lack of global vision has also been mentioned in the cases of RL, SB, Disa and CE $[39,46]$. These authors found that thinking was more linear than circular, with a lack of lateral thinking and an ignorance of life-cycle thinking. The lack of trust in De, RL, the 3Rs, and CDW management is described by [25,70]. Additionally, these authors noticed a lack of acceptance of reclaimed materials. In particular, there is an impatience to get a return on investment quickly, which creates an unfavourable business culture in the case of RL [25]. The last social barrier is the resistance to change, spotted by many authors who focused on the use of Cy (constructability), De, RL, SB, the 3Rs and PFA [37,44,46,51,52,54,61]. Moreover, these authors highlighted scepticism and a preference for traditional methods within the industry, leading to a natural resistance to change from the manufacturers, builders and owners. This resistance to change, common 
to six approaches, is also seen within the organisations that lack the effort necessary to innovate. Unsurprisingly, the lack of experienced, skilled workers and insufficient knowledge is common to five approaches (Figure 2).

Some barriers are related to "consumer society behaviours". These include, for example, the fear of the additional costs of better waste management [46], or the belief that waste is inevitable [30], or the disbelief in the potential utility of a constructability program [54]. Some authors have added that the consumer culture and attitudes towards the quality of salvaged and used items are also an obstacle [25]. For the RL, 3Rs and PFA approaches, the bad image of salvaged materials was reported to be an important barrier [51]. At a broader level, many authors have noticed a lack of awareness for several approaches, such as SB, the 3 Rs and CDW minimisation $[46,60]$. Other authors have noticed the lack of awareness of the benefits of using Cy, RL and CE [59,61]. A lack of concern was raised by several authors for the De, RL and SB approaches $[46,52,66,68]$. Moreover, the lack of understanding of deconstruction and SB was reported by Zaman et al. (2018) [66], as well as [46]. In addition, and specifically for deconstruction, the demolition contractor's culture was highlighted as a critical issue [37].

\subsection{Organisational Barriers}

Organisational barriers refer to the hindrance to the flow of information between stakeholders and between construction phases that negatively impact the efficiency of a project. Organisational barriers include the extra time, resources and effort necessary for the consideration of sustainability and circularity throughout the asset lifecycle. They are the most documented barriers in the articles studied and are found to be attributed to 14 of the 18 approaches (Figure 3).

\subsubsection{Working Methods and the New Approach}

Approximately fifty statements from different authors that deal with issues associated with the current linear approach have been found. The barriers that they detail are raised by the fragmentation of the sector and its inappropriate organisation (Figure 3). The factors cited are the lack of a holistic approach, safety in the deconstruction process, innovation, effective methods, and lifecycle performance focus (Figure 3). When dealing with RL, some authors have noticed the lack of support from the management, as well as immaturity and low investment in knowledge management, information systems, and continuous planning owing to changes in the materials' source location [25]. In addition, some authors reported a lack of specific budgetary allocation for CDW management [60]. Most of the abovementioned barriers are related to the adoption of new approaches and new methods involving more collaboration, communication and holistic and effective strategies. For example, as stressed by some authors, the implementation of RL is a challenge for designers [25]. As a result, multidisciplinary teamwork becomes central and requires appropriate management.

\subsubsection{Multidisciplinary Teamwork and Management}

Many authors have highlighted the need for new methods to improve teamwork when addressing the whole lifecycle of a building $[44,46,50,52,54,58,62,66]$. Those concerns are related to $\mathrm{Cy}$, De, CL (closed loop), RL, SB, the 3Rs and CDW minimisation. For example, some authors identified the need to change the established design and construction processes to promote the reuse of building components [44]. One paper has mentioned the need for systematic cooperation, while a multidisciplinary approach has been discussed in the case of IFD [52,71,72]. This is supported by authors who studied the decision-making framework used in the steel industry, and for the system thinking used in the construction industry $[52,71,72]$. 


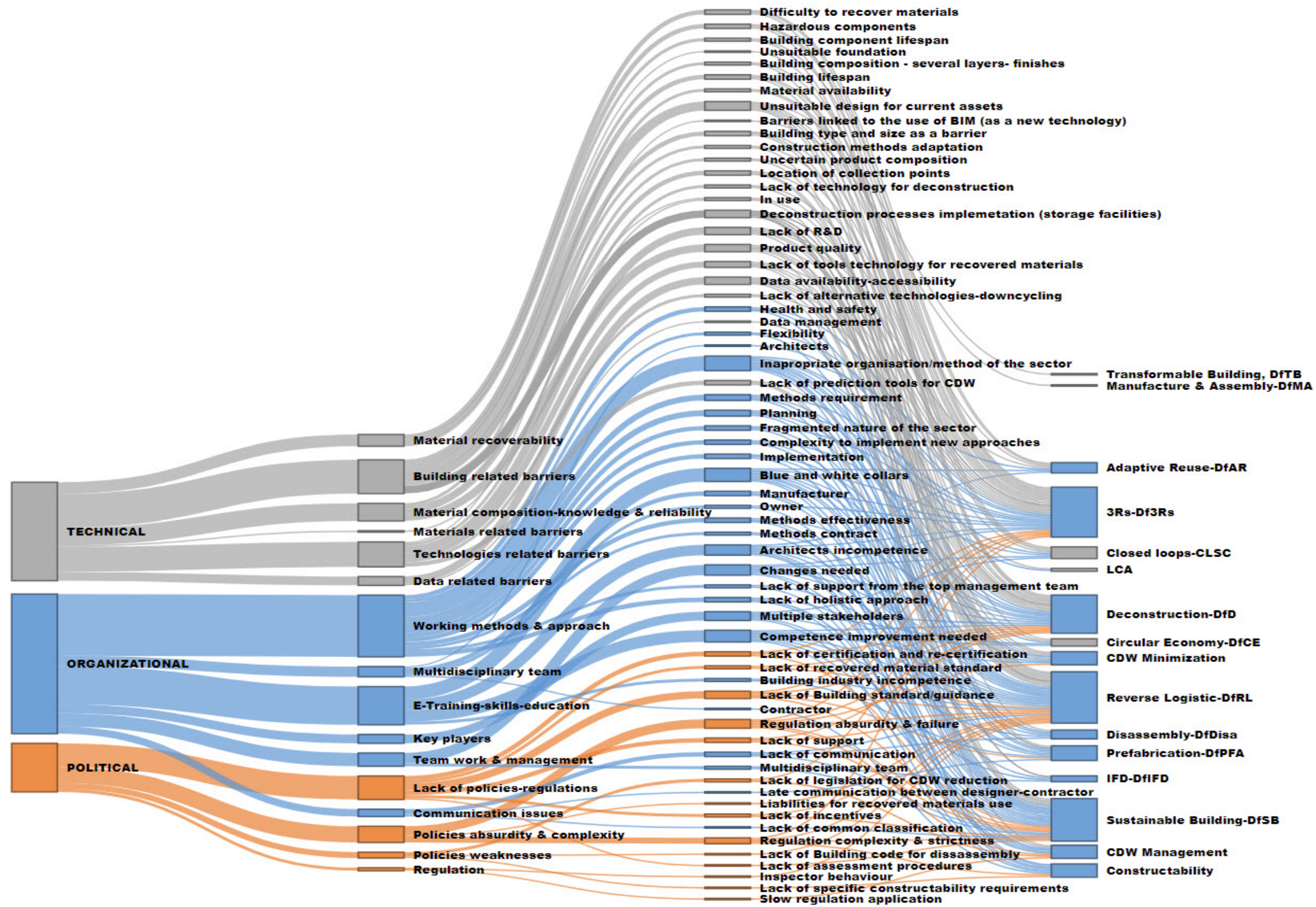

Figure 3. Outline of the technical, organisational and political barriers to the alternative approaches found in the literature. 
Some authors have found that there is a lack of communication between the members of the project teams for RL, SB, Disa and PFA $[46,51,56]$. Specifically, issues related to late communications between the designer and contractor have been identified for RL, SB and PFA, where early collaboration between architects, contractors and manufacturers is required [51].

\subsubsection{Key Players}

Other barriers are related to the large number of stakeholders, and these have been outlined for many approaches, such as Cy, De, CL, RL, SB, CE and the 3Rs by [46,52,54,61]. The barriers are mainly specific to architects (although they also impact other stakeholders, such as contractors), where the reuse of materials in buildings requires acceptance and change in the design and construction processes [44]. Additionally, other authors have listed a number of the barriers raised by the contractors when implementing Cy. Most of them are linked to communication issues and a lack of skills/knowledge [54]. The manufacturers' lack of involvement and responsibility to minimise waste is stressed by [40]. The supply chain is also a central concern for many authors, including a lack of suppliers for PFA [51] and supply chain complexity in the case of SB [46]. Kifokeris and Xenidis [54] have also listed several barriers specific to the owners in the case of $\mathrm{Cy}$, among others. Regarding the 3Rs approach, the unwillingness of the client to spend money upfront when purchasing materials, at a stage where the contractor is often not appointed yet, is a real issue for several authors $[44,54]$.

\subsubsection{Training, Skills and Education Support for a Skilled Workforce}

The lack of skills, from an organisational point of view, is different from the skills related to social background already cited in Section 3.2. Logically, obstacles related to competence improvement were also cited with the lack of lessons learned on:

1. The comprehension of SB [46].

2. The application of DfDisa (design for disassembly), which is restrained by uncertainties regarding its global benefits and financial viability [34].

3. How RL remains unexploited or limited in the construction industry [36].

In complement, some authors have spotted the lack of documentation to support competence improvement, referencing:

1. The lack of lessons learned regarding documentation for Cy [54].

2. The lack of empirical evidence to support the widespread use of RL [36].

3. The need for the identification of demonstration projects to illustrate the potential of the different methods $[37,61]$.

4. The lack of IFD studies for high-rise buildings [52].

5. The lack of studies providing clear instructions on how BIM could be used for CDW management [52].

6. The lack of studies that quantitatively demonstrate the effectiveness of the pre-project definition for buildings in the CE context [61].

From this subsection, the managerial implications involved in the shift to CE can be extracted. They consist in mainly revising the whole lifecycle management of an asset to ensure consistency in management from the early design stage to the EOL phase of the asset. These implications affect the role of all the stakeholders, encouraging them to improve the sharing of the information, even after the EOL phase of the asset, with training/education to help them change their way of working.

\subsection{Technical Barriers}

The technical barriers are split into different scales corresponding to subcategories, from the building scale to the material scale and from data management to the technologies used (Figure 3). 


\subsubsection{Building-Related Barriers}

The long lifecycle of buildings exceeds the lifespan of industrial products and also results in multiple changes of ownership [25,52]. Additionally, the unicity of each building generates a complexity that is difficult to overcome in the modern context [35-37,44]. Firstly, in the design phase, some authors emphasise the barriers related to the designs of buildings that were not made with the SEOL in mind [35]. This includes all of the components, even the foundations, which are most of the time made with concrete [64]. The necessity of adapting the construction methods is emphasised when using reclaimed materials because it adds a whole new level of complexity to the project [44]. One example is given with the use of the in situ connection between precast concrete elements [52]. In the in-use phase, building components are updated or replaced at different intervals during the building's lifetime, adding complexity when updating the data related to the building (e.g., finishes at five-year intervals, lighting at ten-year intervals, HVAC systems at twenty-year intervals, etc.) [66].

Deconstruction processes encounter limitations due to the space available to manage the process and, significantly, to store the materials (see also the section on environmental and economic barriers on this point). The lack of recovery facilities and infrastructure is cited by $[25,64]$. Deconstruction is more complex than demolition, especially in the case of non-prefabricated components [35], sometimes leading to the impossibility of reusing components [56]. Moreover, demountable connections do not always ensure the possibility of deconstruction, and, in general, the poor connection of these elements is an issue $[35,38,52]$. Lastly, few demonstration projects have been identified that can help illustrate the potential of the different methods [25,44,49]. As a result, all these issues are increasing the risks associated with the deconstruction process $[25,39,44]$.

\subsubsection{Material-Related Barriers (Including Data)}

Some barriers are related to the low quality of materials, the poor reliability of the characteristics of recovered materials $[25,41,49,53,58,60,66]$ and the lack of data available for several asset phases. Indeed, in the design phase, the lack of data prevents carrying out an efficient LCA for the EOL phase [32]. In the deconstruction phase, projects and processes are also impacted by a lack of data [35]. At a different level, the behaviour and durability of recycled concrete is difficult to predict accurately without enough data [58]. Importantly, the composition of buildings at the end of their life is essential [47] and the lack of national data on CDW must be overcome [41]. In addition to the lack of data (availability and accessibility), weak data management has also been pointed to by several authors as a concern, especially in the case of national data collection and reporting on CDW [66]. In addition to the general lack of data, there are barriers regarding the limited locations of collection points for recovered materials $[35,39,51,52]$ that generate limitations to material availability [44]. The main source of these issues is the recoverability of construction materials, which is limited by several factors:

1. The use of finishes on building materials reduces the possibility of reusing such materials [31].

2. The use of concrete [37,52].

3. The deconstruction process damages the materials because it is difficult to separate the composites $[43,52,56,58,70]$.

4. Contamination with hazardous materials $[25,39,43,56]$.

5. The deterioration rates are unknown $[3,25,35,37]$.

6. The under-estimation of the resources embedded in the building [61].

\subsubsection{Technology-Related Barriers}

Regarding technological barriers, most of them are related to the lack of appropriate tools and procedures. Although one barrier concerning the lack of prefabricated building designs with BIM tools was reported by [65], most of the other issues are not related to BIM, but to the lack of several other elements. For example, some authors pointed to the 
lack of a common framework and automatic calculation procedures for SB [46], whereas other authors stressed the absence of simple processes to reuse a building project [61]. A lack of science-based, user-friendly tools for De, SB and CE was also reported in many studies $[37,46,61]$, as well as the unavailability of proven alternative technologies [46]. Some authors reported the lack of tools for designers that would otherwise enable efficient deconstruction $[25,37,52,58]$, help with assessing DW generation $[30,55,66]$, promote the inclusion of new techniques for construction [44,46,61], and help with assessing the costs associated with IFD buildings [48]. Lastly, techniques for reusing reclaimed materials are also missing $[25,37,43,48]$. Meanwhile, down-cycling cannot be regarded as a closedloop (CL) approach because of the excessive loss of material value [62].

\subsection{Political Barriers}

Figure 3 outlines the barriers found in the political category. The main subcategory is the lack of appropriate standards (policies and regulation) and is cited in the cases of $\mathrm{Cy}$, De, CL, RL, SB, the 3Rs, CDW management and PFA [58]. This includes shortcomings in standardised processes, insufficient sharing of the best practices, little clear information and little guidance for designers about the design and procurement procedures that they should adopt when reusing components. The lack of guidance for sustainability in public facilities for facility managers is reported by [46].

The lack of recertification, legal warranties and residual performance analysis of recovered building materials has been noted by Couto and Couto (2010) in the particular cases of $\mathrm{De}, \mathrm{SB}$, and the $3 \mathrm{Rs}$, especially when compared to conventional processes. Furthermore, the lack of fiscal incentives or support from governments is cited by $[25,46,66]$ for De, RL and SB. Lastly, the lack of appropriate assessment procedures for architectural competitions, the assessment process being performed late during the design phase and the lack of labelling/measurement standards are shortcomings spotted by [46] for SB.

Some authors argued that the current regulation is too strict to allow innovation, which is a barrier for Cy, De, RL, SB, CDW minimisation and CDW management. Lastly, one paper noted that that building inspectors discourage the use of salvaged materials in the case of RL [47], and another author argued that regional governments are slow to apply CDW management plans which have already been approved [60].

\section{Conclusions and Perspectives}

The debate regarding the implementation of the circular economy (CE) in the architecture, engineering and construction (AEC) sector is relatively new. However, there are already several publications that link the $\mathrm{CE}$ with specific alternative approaches that take into account the lifecycle management of assets from design to end-of-life. These alternative approaches (prefabrication, design for change, design for deconstruction, reverse logistics, waste management and closed-loop systems) directly take into account the asset's end-of-life in the design stage, or only consider the manufacture and assembly phase (but may still ease the deconstruction process). Eighteen such approaches have been found that are far from dominant. However, helping them overcome the obstacles that they face may help to remove the future barriers of applying the $\mathrm{CE}$ concept to the built environment.

This article has assessed the barriers to those 18 approaches identified in the literature. The barriers were classified into six categories (economic, sociological, political, organisational, technological, and environmental). The interrelation between the barriers from different categories is very common due to the holistic nature of the construction lifecycle, and this has been illustrated here by two Sankey diagrams. The barriers are also related to the diversity of stakeholders and the phases of the building process.

The organisational barriers are the most cited in this review, and deal with the difficulty with changing the working methods and managing the required teamwork and the multidisciplinary approach. The last series of organisational barriers are linked to the lack of training and support for the skilled workforce and the provision of education. Increased access to data should help to revise the current management of the asset lifecycle. 
The socioeconomic barriers are linked to the lack of awareness and demand for alternative approaches. The other socioeconomic barriers are related to people's behaviour (e.g., resistance to change and cultural beliefs), and lastly to the higher cost of alternative approaches (and the seeking of profit first). The political barriers are mainly related to the lack of appropriate standards and policies.

Some of the technical barriers are related to the construction materials (composition knowledge and recoverability) and others to the building scale (e.g., construction methods, project phase adoption and building lifespan). Other barriers are related to data and information management. The last range of technical barriers is linked to a lack of appropriate technology. The barriers linked to the environment are related to the site constraints (limited space), and to the use of non-recoverable materials. Pollution related to the materials (e.g., lead and asbestos) is also cited. Finally, this review gives a detailed map of the interrelations of the barriers that would help stakeholders develop strategies to overcome the current obstacles as they shift to a CE in the AEC sector.

The Sankey diagrams embed information regarding the structuring of the relationship between the barriers of a wide range of approaches. This information may help with the design of new research programmes that question the professionals working in the AEC sector about the barriers to (or the drivers that would foster) the transition to a CE. Moreover, the Sankey diagrams can help policymakers (and therefore standardisation bodies) design appropriate policy (and therefore standards) to foster the shift to a CE in the AEC sector. This information can also be useful to help develop and trigger green finance, which is a means supported by the United Nations to contribute towards delivering several of its sustainable development goals.

The key limitation of this study is that the secondary data analysed cover a wide range of geographic areas, meaning that some of the results may not fit any countries. However, the globalisation of the economy is a factor that would favour the consistency of the study across the world. Another limitation is that the studied approaches may not be consistent with a strict CE framework, knowing that there is no consensus on the definition or implementation of the CE in the AEC sector, especially given the lack of ISO standards on that topic. In this perspective, it should be evidenced also the role of digital technologies (under the umbrella of Industry 4.0 or BIM in the specific context of the AEC sector) in supporting the measurement of performance and data management to sustain the CE.

Author Contributions: Conceptualisation, R.C.; methodology, R.C.; formal analysis, R.C.; data curation, R.C.; writing—original draft preparation, R.C.; writing-review and editing, R.C., J.-C.M. and K.R.; visualisation, R.C. All authors have read and agreed to the published version of the manuscript.

Funding: This research received no external funding.

Institutional Review Board Statement: Not applicable.

Informed Consent Statement: Not applicable.

Conflicts of Interest: The authors declare no conflict of interest.

\section{References}

1. Friess, W.A.; Rakhshan, K. A review of passive envelope measures for improved building energy efficiency in the UAE. Renew. Sustain. Energy Rev. 2017, 72, 485-496. [CrossRef]

2. Villa, S.; Sassanelli, C. The Data-Driven Multi-Step Approach for Dynamic Estimation of Buildings' Interior Temperature. Energies 2020, 13, 6654. [CrossRef]

3. Rakhshan, K.; Morel, J.-C.; Alaka, H.; Charef, R. Components reuse in the building sector-A systematic review. Waste Manag. Res. 2020, 38, 347-370. [CrossRef]

4. Kibert, C.J. Sustainable Construction: Green Building Design and Delivery; John Wiley \& Sons: New York, NY, USA, 2016.

5. Osmani, M. Construction Waste Minimization in the UK: Current Pressures for Change and Approaches. Procedia-Soc. Behav. Sci. 2012, 40, 37-40. [CrossRef]

6. Charef, R.; Alaka, H.; Emmitt, S. Beyond the Third Dimension of BIM: A Systematic Review of Literature and Assessment of Professional Views. J. Build. Eng. 2018, 19, 242-257. [CrossRef] 
7. Geissdoerfer, M.; Savaget, P.; Bocken, N.; Hultink, E.J. The Circular Economy-A new sustainability paradigm? J. Clean. Prod. 2017, 143, 757-768. [CrossRef]

8. Ellen MacArthur Foundation. Available online: https:/ / ellenmacarthurfoundation.org/ (accessed on 10 November 2021).

9. Geng, Y.; Doberstein, B. Developing the circular economy in China: Challenges and opportunities for achieving 'leapfrog development'. Int. J. Sustain. Dev. World Ecol. 2008, 15, 231-239. [CrossRef]

10. Rosa, P.; Sassanelli, C.; Terzi, S. Towards Circular Business Models: A systematic literature review on classification frameworks and archetypes. J. Clean. Prod. 2019, 236, 117696. [CrossRef]

11. Mhatre, P.; Panchal, R.; Singh, A.; Bibyan, S. A systematic literature review on the circular economy initiatives in the European Union. Sustain. Prod. Consum. 2021, 26, 187-202. [CrossRef]

12. Potting, J.; Hekkert, M.; Worrell, E.; Hanemaaijer, A. Circular Economy: Measuring Innovation in the Product Chain. Available online: http: / www.pbl.nl/sites/default/files/cms/publicaties/pbl-2016-circular-economy-measuring-innovation-in-productchains-2544.pdf (accessed on 10 November 2021).

13. Friant, M.C.; Vermeulen, W.J.; Salomone, R. Analysing European Union circular economy policies: Words versus actions. Sustain. Prod. Consum. 2021, 27, 337-353. [CrossRef]

14. Pomponi, F.; Moncaster, A. Circular economy for the built environment: A research framework. J. Clean. Prod. 2017, 143, 710-718. [CrossRef]

15. Charef, R.; Lu, W. Factor dynamics to facilitate circular economy adoption in construction. J. Clean. Prod. 2021, $319,128639$. [CrossRef]

16. Iacovidou, E.; Velis, C.A.; Purnell, P.; Zwirner, O.; Brown, A.; Hahladakis, J.; Millward-Hopkins, J.; Williams, P.T. Metrics for optimising the multi-dimensional value of resources recovered from waste in a circular economy: A critical review. J. Clean. Prod. 2017, 166, 910-938. [CrossRef]

17. Ghisellini, P.; Ji, X.; Liu, G.; Ulgiati, S. Evaluating the transition towards cleaner production in the construction and demolition sector of China: A review. J. Clean. Prod. 2018, 195, 418-434. [CrossRef]

18. Cai, G.; Waldmann, D. A material and component bank to facilitate material recycling and component reuse for a sustainable construction: Concept and preliminary study. Clean Technol. Environ. Policy 2019, 21, 2015-2032. [CrossRef]

19. Sassanelli, C.; Urbinati, A.; Rosa, P.; Chiaroni, D.; Terzi, S. Addressing circular economy through design for X approaches: A systematic literature review. Comput. Ind. 2020, 120, 103245. [CrossRef]

20. Ruiz, L.A.L.; Ramón, X.R.; Domingo, S.G. The circular economy in the construction and demolition waste sector-A review and an integrative model approach. J. Clean. Prod. 2020, 248, 119238. [CrossRef]

21. Osobajo, O.A.; Oke, A.; Omotayo, T.; Obi, L.I. A systematic review of circular economy research in the construction industry. Smart Sustain. Built Environ. 2020. [CrossRef]

22. Charef, R.; Emmitt, S. Uses of building information modelling for overcoming barriers to a circular economy. J. Clean. Prod. 2021, 285, 124854. [CrossRef]

23. Dokter, G.; Thuvander, L.; Rahe, U. How circular is current design practice? Investigating perspectives across industrial design and architecture in the transition towards a circular economy. Sustain. Prod. Consum. 2021, 26, 692-708. [CrossRef]

24. Charef, R.; Ganjian, E.; Emmitt, S. Socio-economic and environmental barriers for a holistic asset lifecycle approach to achieve circular economy: A pattern-matching method. Technol. Forecast. Soc. Chang. 2021, 170, 120798. [CrossRef]

25. Chileshe, N.; Rameezdeen, R.; Hosseini, M.R.; Lehmann, S. Barriers to implementing reverse logistics in South Australian construction organisations. Supply Chain Manag. Int. J. 2015, 20, 179-204. [CrossRef]

26. Zou, P.; Hardy, R.; Yang, R. Barriers to building and construction waste reduction, reuse and recycling: A case study of the Australian Capital Region. In Building Today-Saving Tomorrow, Proceedings of the Sustainability in Construction and Deconstruction Conference, Auckland, New Zealand, 15-17 July 2015; Panko, M., Kestle, L., Eds.; Unitec Institute of Technology: Auckland, New Zealand, 2015; pp. 27-35.

27. Hossain, U.; Ng, S.T.; Antwi-Afari, P.; Amor, B. Circular economy and the construction industry: Existing trends, challenges and prospective framework for sustainable construction. Renew. Sustain. Energy Rev. 2020, 130, 109948. [CrossRef]

28. Schlosser, R.W. Appraising the Quality of Systematic Reviews. In Focus: Technical Briefs; Held South-West Educational Development Laboratory. Available online: https://ktdrr.org/ktlibrary/articles_pubs/ncddrwork/focus/focus17/ (accessed on 28 May 2021).

29. Grant, M.J.; Booth, A. A typology of reviews: An analysis of 14 review types and associated methodologies. Health Inf. Libr. J. 2009, 26, 91-108. [CrossRef] [PubMed]

30. Ajayi, S.O.; Oyedele, L.O.; Bilal, M.; Akinade, O.O.; Alaka, H.A.; Owolabi, H.A.; Kadiri, K.O. Waste Effectiveness of the Construction Industry: Understanding the Impediments and Requisites for Improvements. Resour. Conserv. Recycl. 2015, 102, 101-112. [CrossRef]

31. Akanbi, L.A.; Oyedele, L.O.; Akinade, O.O.; Ajayi, A.O.; Delgado, M.D.; Bilal, M.; Bello, S.A. Salvaging building materials in a circular economy: A BIM-based whole-life performance estimator. Resour. Conserv. Recycl. 2018, 129, 175-186. [CrossRef]

32. Akinade, O.; Oyedele, L.; Oyedele, A.; Delgado, J.M.D.; Bilal, M.; Akanbi, L.; Ajayi, A.; Owolabi, H. Design for deconstruction using a circular economy approach: Barriers and strategies for improvement. Prod. Plan. Control. 2020, 31, 829-840. [CrossRef]

33. Bouzon, M.; Spricigo, R.; Rodriguez, C.M.; de Queiroz, A.A.; Miguel, P.A.C. Reverse logistics drivers: Empirical evidence from a case study in an emerging economy. Prod. Plan. Control. 2015, 26, 1368-1385. [CrossRef] 
34. Brancart, S.; Paduart, A.; Vergauwen, A.; Vandervaeren, C.; Laet, L.D.; Temmerman, N.D. Transformable Structures: Materialising Design for Change. Int. J. Des. Nat. Ecodyn. 2017, 12, 357-366. [CrossRef]

35. Machado, R.C.; de Souza, H.A.; Veríssimo, G.D.S. Analysis of Guidelines and Identification of Characteristics Influencing the Deconstruction Potential of Buildings. Sustainability 2018, 10, 2604. [CrossRef]

36. Chileshe, N.; Rameezdeen, R.; Hosseini, M.R. Drivers for Adopting Reverse Logistics in the Construction Industry: A Qualitative Study. Eng. Constr. Archit. Manag. 2016, 23, 134-157. [CrossRef]

37. Couto, J.; Couto, A. Analysis of Barriers and the Potential for Exploration of Deconstruction Techniques in Portuguese Construction Sites-Review. Sustainability 2010, 2, 428-442. [CrossRef]

38. Crowther, P. Design for Buildability and the Deconstruction Consequences. In Proceedings of the 3rd Annual Meeting of CIB Task Group 39, Rotterdam, The Netherlands, 9 April 2002; Available online: https:/ /www.iip.kit.edu/downloads/CIB_Publication_272.pdf (accessed on 25 October 2021).

39. Crowther, P. Design for Disassembly-Themes and Principles. In Environment Design Guide; Royal Australian Institute of Architects: Canberra, Australia, 2005; pp. 1-7.

40. Rios, F.C.; Chong, W.K.; Grau, D. Design for Disassembly and Deconstruction-Challenges and Opportunities. Procedia Eng. 2015, 118, 1296-1304. [CrossRef]

41. Diyamandoglu, V.; Fortuna, L.M. Deconstruction of Wood-Framed Houses: Material Recovery and Environmental Impact. Resour. Conserv. Recycl. 2015, 100, 21-30. [CrossRef]

42. Correia, J.M.F.; de Oliveira Neto, G.C.; Leite, R.R.; da Silva, D. Plan to Overcome Barriers to Reverse Logistics in Construction and Demolition Waste: Survey of the Construction Industry. J. Constr. Eng. Manag. 2021, 147, 78620001966. Available online: https:/ / ascelibrary.org/doi/abs/10.1061/\%28ASCE\%29CO.1943-7862.0001966 (accessed on 10 November 2021). [CrossRef]

43. Forsythe, P.J. Drivers of Housing Demolition Decision Making and the Impact on Timber Waste Management. Constr. Econ. Build. 2011, 11, 1-14. [CrossRef]

44. Gorgolewski, M. Designing with reused building components: Some challenges. Build. Res. Inf. 2008, 36, 175-188. [CrossRef]

45. Leigh, N.G.; Patterson, L.M. Deconstructing to Redevelop: A Sustainable Alternative to Mechanical Demolition: The Economics of Density Development Finance and Pro Formas. J. Am. Plan. Assoc. 2006, 72, 217-225. [CrossRef]

46. Häkkinen, T.; Belloni, K. Barriers and drivers for sustainable building. Build. Res. Inf. 2011, 39, 239-255. [CrossRef]

47. Hosseini, M.R.; Chileshe, N.; Rameezdeen, R.; Lehmann, S. Reverse Logistics for the Construction Industry: Lessons from the Manufacturing Context. Int. J. Constr. Eng. Manag. 2014, 3, 75-90.

48. Hosseini, M.R.; Rameezdeen, M.R.; Chileshe, N.; Lehmann, S. Reverse Logistics in the Construction Indus-try. Waste Manag. Res. 2015, 33, 499-514. [CrossRef]

49. Huuhka, S.; Hakanen, J.H. Potential and Barriers for Reusing Load-Bearing Building Components in Finland. Int. J. Hous. Sci. 2015, 39, 215-224.

50. Inglis, M. Construction and Demolition Waste-Best Practice and Cost Saving. SB07 N. Z. 2007, 1, 57.

51. Jaillon, L.C.; Poon, C.-S. Design issues of using prefabrication in Hong Kong building construction. Constr. Manag. Econ. 2010, 28, 1025-1042. [CrossRef]

52. Jaillon, L.C.; Poon, C.-S. Life cycle design and prefabrication in buildings: A review and case studies in Hong Kong. Autom. Constr. 2014, 39, 195-202. [CrossRef]

53. Kibert, C.J. Deconstruction: The Start of a Sustainable Materials Strategy for the Built Environment. Ind. Environ. 2003, 26, 84-88.

54. Kifokeris, D.; Xenidis, Y. Constructability: Outline of Past, Present, and Future Research. J. Constr. Eng. Manag. 2017, 143. [CrossRef]

55. Kim, Y.C.; Hong, W.H.; Park, J.W.; Cha, G.W. An Estimation Framework for Building Information Modeling (BIM)-Based Demolition Waste by Type. Waste Manag. Res. 2017, 35, 1285-1295. [CrossRef] [PubMed]

56. Knecht, B. Designing for Disassembly and Deconstruction. Archit. Rec. 2004, 192, 181-188.

57. Kohler, N.; Yang, W. Long-term management of building stocks. Build. Res. Inf. 2007, 35, 351-362. [CrossRef]

58. Nisbet, M.; Venta, G.; Foo, S. Demolition and Deconstruction: Review of the Current Status of Reuse and Recycling of Building Materials. Air Waste Manag. Assoc. 2012, 1-14.

59. Pulaski, M.; Hewitt, C.; Horman, M.; Guy, B. Design for Deconstruction. Mod. Steel Constr. 2004, 44, 33-37. Available online: https:/ / www.aisc.org/globalassets/modern-steel/archives/2004/06/2004v06_deconstruction.pdf (accessed on 25 October 2021).

60. Merino, M.D.R.; Gracia, P.I.; Azevedo, I.S.-W. Sustainable construction: Construction and demolition waste reconsidered. Waste Manag. Res. 2010, 28, 118-129. [CrossRef] [PubMed]

61. Sanchez, B.; Haas, C. Capital project planning for a circular economy. Constr. Manag. Econ. 2018, 36, 303-312. [CrossRef]

62. Sassi, P. Defining closed-loop material cycle construction. Build. Res. Inf. 2008, 36, 509-519. [CrossRef]

63. Tingley, D.D.; Davison, B. Developing an LCA methodology to account for the environmental benefits of design for deconstruction. Build. Environ. 2012, 57, 387-395. [CrossRef]

64. Xanthopoulos, A.; Aidonis, D.; Iakovou, E.; Vlachos, D.; Iakovou, E. Reverse Logistics Processes of Multi-Type End-of-Life Buildings/Construction Sites: An Integrated Optimization Framework. WSEAS Trans. Environ. Dev. 2009, 5, $250-259$.

65. Yuan, Z.; Sun, C.; Wang, Y. Design for Manufacture and Assembly-Oriented Para-metric Design of Prefabricated Buildings. Autom. Constr. 2018, 88, 13-22. [CrossRef] 
66. Zaman, A.U.; Arnott, J.; Mclntyre, K.; Hannon, J. Resource Harvesting through a Systematic Deconstruction of the Residential House: A Case Study of the 'Whole House Reuse' Project in Christchurch, New Zealand. Sustainability 2018, 10, 3430. [CrossRef]

67. Abdulrahman, M.D.; Gunasekaran, A.; Subramanian, N. Critical barriers in implementing reverse logistics in the Chinese manufacturing sectors. Int. J. Prod. Econ. 2014, 147, 460-471. [CrossRef]

68. Bouzon, M.; Govindan, K.; Rodriguez, C.M.T. Evaluating Barriers for Reverse Logistics Implementation under a Multiple Stakeholders' Perspective Analysis Using Grey Decision Making Approach. Resour. Conserv. Recycl. 2018, 128, 315-335. [CrossRef]

69. Park, J.; Tucker, R. Overcoming barriers to the reuse of construction waste material in Australia: A review of the literature. Int. J. Constr. Manag. 2017, 17, 228-237. [CrossRef]

70. Tingley, D.D.; Cooper, S.; Cullen, J. Understanding and overcoming the barriers to structural steel reuse, a UK perspective. J. Clean. Prod. 2017, 148, 642-652. [CrossRef]

71. Rose, C.; Stegemann, J. From Waste Management to Component Management in the Construction Industry. Sustainability 2018, 10, 229. [CrossRef]

72. Yeung, J.; Walbridge, S.; Haas, C. The role of geometric characterization in supporting structural steel reuse decisions. Resour. Conserv. Recycl. 2015, 104, 120-130. [CrossRef] 